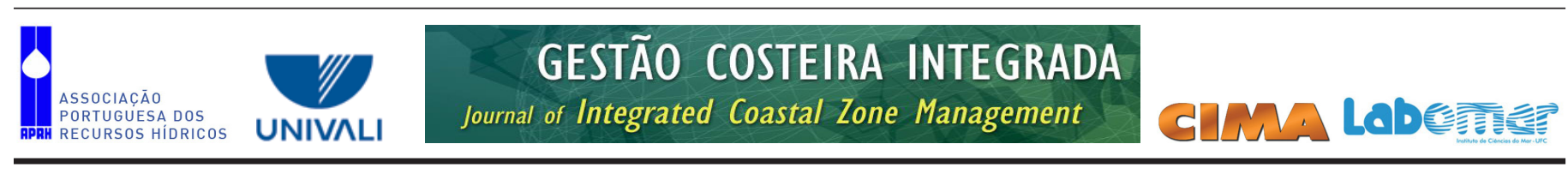

http://www.aprh.pt/rgci/pdf/rgci-405_Koerner.pdf | DOI:10.5894/rgci405

\title{
Efeito de estruturas de contenção à erosão costeira sobre a linha de costa: Balneário Hermenegildo, Rio Grande do Sul, Brasil *
}

\author{
Effect of coastal erosion contention structures on the coastline: \\ Hermenegildo Beach, Rio Grande do Sul, Brazil
}

\author{
K. F. Koerner ${ }^{\circledR, 1}$, U. R. Oliveira ${ }^{2}$, G. Gonçalves ${ }^{3}$
}

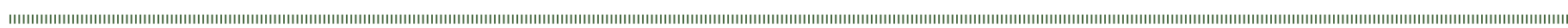

\section{RESUMO}

O balneário Hermenegildo está localizado no extremo sul do Brasil, no município de Santa Vitória do Palmar. Esta praia vem sofrendo um significativo processo de erosão costeira, danificando propriedades situadas à beira mar, fato que vem sendo combatido pelos próprios moradores através da colocação de estruturas de contenção à erosão. Este trabalho tem como objetivo analisar se essas estruturas de contenção dispostas na orla do balneário Hermenegildo estão realmente contendo a erosão costeira e, além disso, qual seu impacto sobre as características da praia nesse trecho. Para isso, foi utilizado um GPS geodésico em módulo de posicionamento relativo cinemático em tempo real (Real Time Kinematic - RTK) para mapear linhas de referência: linhas de dunas na parte urbanizada e junto às dunas frontais nas porçóes sul e norte do balneário, linha d'água ao longo do mesmo trecho e perfis topográficos transversais à costa. Esses dados foram corroborados por outras ferramentas de análise, tais como imagens aéreas, mosaicos de fotografias convencionais e identificação das estruturas de contenção, utilização de um sistema de informações geográficas (SIG), além da própria revisão bibliográfica. Ao analisar as diferenças encontradas entre a posiçáo da linha da base das escarpas na parte urbanizada (zona estruturada) e a linha da base das dunas frontais adjacentes ao norte e ao sul do balneário, foi detectado que parte considerável da orla urbanizada está sobre a pós-praia, com uma área de contenção calculada em $54.100 \mathrm{~m}^{2}$ no ano da medição. Especificamente a porçáo central da orla urbanizada, onde existe maior concentração de estruturas de contenção mais resistentes à erosão costeira (como enrocamentos), está mais projetada sobre a face da praia em relação às áreas adjacentes. Com isso, conclui-se que as estruturas de contenção no balneário, mesmo que colocadas pelos próprios moradores, muitas vezes sem um conhecimento adequado de obras de engenharia costeira, estão contendo, pelo menos parcialmente, a migração horizontal da linha de costa em direção ao continente, embora muitas casas já tenham sido destruídas nos últimos 50 anos e substituídas por áreas de praia. Por outro lado, essa fixação da mobilidade horizontal da linha de costa acarreta impactos na morfologia praial na parte que está mais impactada pelas estruturas, como diminuiçáo da largura da praia, ausência de bermas, o que diminui a declividade na face da praia, e presença de escarpas íngremes no limite superior, entre a praia e a área urbana. Durante a medição realizada, a linha d'água apresentou uma concavidade em frente ao setor central, o que indica que ocorre uma retirada de sedimentos nas áreas junto às estruturas de contenção. Tal característica apresenta-se bastante dinâmica espaço-temporalmente e necessita ser mais bem analisada. Com o progressivo avanço marinho sobre uma área urbana projetada sobre a praia, com progressiva diminuição entre a linha de quebra de ondas e as estruturas de contenção e área urbanizada, torna-se apropriado refletir sobre estratégias de contenção à erosão para médio e longo prazo, com um efetivo planejamento territorial e ambiental.

Palavras-chave: GPS-RTK, Linhas de costa, Morfodinâmica costeira, Gerenciamento Costeiro, SIG

@ - Corresponding author

1 - FURG - Universidade Federal do Rio Grande, Programa de Pós-graduação em Gerenciamento Costeiro. e-mail: karlkoerner@gmail.com

2 - FURG - Universidade Federal do Rio Grande, Instituto de Ciências Humanas e da Informação. e-mail: ulisseslicke@yahoo.com.br

3 - FURG - Universidade Federal do Rio Grande, Centro de Ciências da Computação.e-mail: glaubergoncalves@gmail.com 


\section{ABSTRACT}

Hermenegildo beach, located in Santa Vitória do Palmar, Rio Grande do Sul state, in the extreme south of Brazil (fig. 1), has been undergoing a significant problem of coastal erosion that started at the end of the 50's and has gotten worse since the 90's. It has damaged seashore properties whose owners have faced this situation by armoring their properties with containment structures against the erosion (fig.2). This study aimed at analyzing whether the containment structures along Hermenegildo beach have actually hold coastal erosion and what impact they have on the characteristics of this stretch of beach. In order to carry it out, a geodesic GPS in real time kinematic (RTK) mode was used to map the so-called reference lines: all the upper limit of the beach in the urbanized part (limit of slopes and containment structures on the beach) and the upper limit of the beach along the frontal dunes in the south and the north of the urban area (the basis of the frontal dunes) on a coastal stretch that is about $5 \mathrm{~km}$ long; the high waterline along the same stretch (fig.5); an interpolated line was done linking linear regression made with the GPS points from foredunes from north and south of the urbanized part (fig.6). Additionally, 22 topographic profiles which are transversal to the beach were mapped, in order to investigate the morphological differences of the slopes found in this study (fig.7). These data were supported by data collected by other tools, such as aerial images, mosaics of conventional photographs and the identification of containment structures, the use of a Geographic Information System (GIS) and by the literature review itself. Points marked by the GPS in sectors called North Dunes and South Dunes have shown that the upper limit of the beach with these dunes has a relatively straight conformation on the map, similar to what is expected from a natural environment in that place (where most beaches are quite straight or oblong, except for washout channels which generate little recesses). However, the Urbanized Shore sector has a very irregular upper limit on the beach due to different shapes of containment structures or even to their absence on this stretch. The analysis of the differences found between the upper limit of the beach in the urbanized part (structured zone) and the one close to the frontal dunes in the south and the north of the urban area showed that the central part of the urbanized shore - where there is the largest number of containment structures, such as rockfill, which are more resistant to coastal erosion - advances over the shoreline, by comparison with the adjacent areas, and comprises a containment area of $54,100 \mathrm{~m}^{2}$ in the period under analysis (fig.8). The longest distance between the Urbanized Shore sector and the interpolated dune line was 45.3 meters (fig. 8, 'M'). Therefore, this study concluded that the containment structures on the beach, even though they were built by dwellers that did not have specific knowledge about coastal engineering, have hold, at least partially, the horizontal migration of the shoreline towards the landside, although several houses have already been destroyed and replaced by beach areas over the past 50 years. It must be highlighted that the authors of this study do not stimulate this kind of construction in other urbanized coasts. However, there is evidence that the protection structures, such as rockfill, have been efficient in Hermenegildo since they held the erosive process in that place, at least in the period under investigation. On the other hand, fixing the horizontal mobility of the coastline leads to significant impacts on the beach environment, mainly in the morphology of the part that has been more affected by the structures. Impacts comprise the decrease in the beach width, no berms - a fact that diminishes the declivity on the beach face - and steep slopes on the upper limit of the beach (fig.9); thus, it gets harder to gain access to the beach. During the measurement, the waterline had a concavity in front of the central area (fig.8); it means that sediment has been removed from the areas close to the containment structures and that they interfere with the sediment balance in the horizontal plane besides generating vertical sediment deficit. Such concavity seems to be quite dynamic in terms of space and time; thus, a deeper analysis is needed. The short distance from the coast to the waterline (fig. $8, \underline{m}$ ') was related to the projection of the containment structures and the concavity of the waterline. The beach area is very small, not only for the dissipation of the wave energy but also for the users' leisure, i. e., the natural shore has been thoroughly suppressed, a situation that is not considered adequate to that place. In addition, since there is progressive advance of the sea over the projected area and progressive reduction between the swash zone and the containment structures in the urbanized area, it is not known how long these structures are going to keep protecting the urban area. Therefore, it is necessary to reflect on longterm management strategies along with effective environmental planning to account for future constructions. Regarding the material and methods employed in the study, it is worth mentioning that the GPS-RTK is a very efficient and precise tool which enables researchers to collect numerous data quickly. In fact, all positioning data - that referred to the GPS - used in this study could be collected on one day in situ. Even though errors may occur, they can be considerably mitigated.

Keywords: GPS-RTK, Shorelines, Coastal morphodynamics, Coastal Zone Management, GIS.

\section{INTRODUÇÁO}

O problema da erosão costeira pode ser caracterizado, sob o ponto de vista do planejamento e da gestão, como um conflito de uso do espaço, nesse caso, de uma linha de costa móvel. A configuração desse conflito se dá, basicamente, através da oposição das forçantes ambientais e das tendências de uso e ocupação antrópica desse espaço. De um lado, a natureza age movendo a linha de costa de modo que se adapte a forçantes como tempestades, balanço de sedimentos e elevação do nível do mar; e, do outro, o ser humano age para fixá-la, no intuito de proteger o patrimônio construído e ameaçado pela erosão.

São diversas as abordagens utilizadas para lidar com o problema da erosão costeira (NRC, 1990; Pilarczyk, 1990;
USACE, 2008; Linham \& Nicholls, 2010). Essas abordagens podem seguir duas lógicas diferentes: (i) interferir na dinâmica marinha e costeira ou (ii) interferir na organização humana, deixando a dinâmica marinha agir naturalmente. Exemplos da primeira abordagem são proteger e estabilizar a linha de costa com métodos rígidos (blocos de concreto, muros de proteçáo, espigóes e quebra-mares) ou recuperar a praia com métodos flexíveis (engorda de praia). Na segunda abordagem, o ser humano recua as construçóes (adaptandose à dinâmica da costa) ou deixa como está (abstém-se de manejo planejado).

No entanto, para se decidir e tomar uma iniciativa sobre qual abordagem utilizar, gestores e engenheiros costeiros necessitam de uma quantificação da erosão costeira no local de manejo, com séries de dados mensuráveis. Nesse quesito, 
também é possível a utilização de diversos métodos, desde perfis praiais, utilização de fotografias aéreas e imagens de satélite, até métodos de medição e monitoramento de variação de linhas de costa com o uso de GPS de alta precisão $\mathrm{e}$, mais recentemente, a realização de mapeamentos a laser (LIDAR) altamente sofisticados com emprego de avióes ou helicópteros (Boak \& Turner, 2005).

No balneário Hermenegildo, a erosáo costeira como um problema está presente desde o final da década de 1950, quando ocorreu a primeira grande destruição de casas causada por uma tempestade marinha de alta energia (Koerner, 2009). Desde entâo, os proprietários das casas à beira-mar vêm construindo, de modo individual, isto é, sem um planejamento governamental ou ação integrada, diversas formas de estruturas de proteção e de diferentes materiais, como pneus, estacas e muros de madeira, e, a partir da década de 1990, com estruturas mais reforçadas, como enrocamentos e muros de concreto (Esteves et al., 2000; Teixeira, 2007, Koerner, 2009). A lógica consiste em que cada detentor de casa ou terreno à beira mar tente fixar a linha de costa, dentro das suas possibilidades financeiras e dentro dos seus limites de terreno voltados para o mar.

Apesar de os métodos de contençáo utilizados pelos proprietários terem sido construídos sem projetos de engenharia específicos para isso, ao observar o balneário Hermenegildo pela praia e à certa distância, vindo tanto pelo norte (da praia dos Concheiros) como pelo sul do balneário (deslocando-se a partir da Barra do Chuí), percebe-se que o referido balneário parece estar projetado em direção ao mar. Desse modo, foi questionado se isso ocorre devido à relativa fixação da linha de costa pelas estruturas construídas para conter a erosão. Com base nesse questionamento central, o presente estudo tem como objetivo analisar se as estruturas de contenção dispostas na orla do balneário Hermenegildo estão realmente contendo a erosão costeira e, além disso, qual seu impacto sobre as características da praia nesse trecho.

\section{2. ÁREA DE ESTUDO}

O balneário Hermenegildo (Fig. 1) faz parte do município de Santa Vitória do Palmar, no Estado do Rio Grande do Sul, extremo sul do Brasil. Está situado aproximadamente a $33^{\circ} 40^{\prime} \mathrm{S}$ e $53^{\circ} 15^{\prime} \mathrm{W}$, a 18 quilômetros da sede do município e a apenas 12 quilômetros da fronteira com o Uruguai. O principal acesso ao balneário se dá pela rodovia RS-833.

A Planície Costeira do Rio Grande do Sul (PCRS), onde se insere a área de estudo, possui 620 quilômetros de extensão e uma largura que varia de 15 a 100 quilômetros. A PCRS compreende uma série de quatro barreiras costeiras justapostas e formadas no Quaternário nos últimos $400 \mathrm{mil}$ anos, sendo a barreira quatro a atual e mais recente, com aproximadamente 7 mil anos (Tomazelli \& Villwock, 2000). $\mathrm{O}$ balneário Hermenegildo se encontra inteiramente sobre o sistema deposicional Holocênico (barreira IV). Tal sistema é o mais recente do gênero e, portanto, o que apresenta maior dinâmica, pois ainda se encontra em formação.

Essa barreira holocênica apresenta uma contínua linha de costa arenosa, dominada por ondas, sendo apenas interrompida por redes de drenagem (desembocaduras lagunares e canais sangradouros). Apesar da relativa homogeneidade, essa barreira apresenta duas áreas de projeção da costa, onde ocorrem campos de dunas transgressivas, e duas áreas de reentrância, onde predominam cordões litorâneos (Dillenburg et al., 2000) (Fig. 1).

Ao sul dessas duas projeçóes da linha de costa da PCRS, foram identificadas as maiores intensidades das correntes de deriva litorânea, com 2,7 milhóes $\mathrm{m}^{3}$ /ano de sedimentos removidos na área entre o Balneário Hermenegildo e o farol do Albardão e 2,9 milhóes $\mathrm{m}^{3} /$ ano na região entre o Balneário Mar Grosso e o farol da Solidão (Lima et al., 2001). Na praia do Hermenegildo, o ângulo de orientação da linha de costa em relação ao norte é de $48^{\circ}$ (Pereira et al., 2010), indicando que esta praia recebe, quase que frontalmente, as ondulaçóes de maior energia provenientes do quadrante sul (swell) (Romeu et al., 2011), fazendo com que a deriva de sedimentos resultante seja para o norte. Essas ondas podem chegar acima de 6 metros de altura em águas profundas pelo menos uma vez ao ano (Machado et al., 2010).

Os setores ao sul das grandes projeçóes correspondem às áreas da planície costeira do Rio Grande do Sul com erosão mais severa e evidente (Tomazelli et al., 1998). Speranski \& Calliari (2006) sugerem que essa severa erosão ocorra devido à existência de uma concentração da energia de ondas nas porçôes ao sul destas duas projeçóes (praias do Hermenegildo e do Farol da Conceição) devido aos processos de refração de ondas causada pela batimetria do local, o que gera um foco de ondas sobre a praia. Embora esse trecho de costa apresente amplitude média de maré de menos de 0,5 metros, o clima de ondas e ventos corrobora para que as marés meteorológicas variem até $1,9 \mathrm{~m}$ acima da maré astronômica (Parise et al., 2009). As marés mais elevadas podem causar erosão na faixa de praia, principalmente após a passagem de ciclones que mantêm o nível do mar elevado por muitas horas (Calliari et al., 1998; Parise et al., 2009).

Para Lima et al., (2013), os quais apresentaram um modelo evolutivo para a região da praia do Hermenegildo, através de análises estratigráficas e datação de carbono ${ }^{14}$, a erosão nesse segmento da costa está associada a duas principais fases: A primeira fase, de $17,5 \mathrm{ka}$ até $6,7 \mathrm{ka}$, controlada pela subida do nível do mar entre o final do Pleistoceno e o início do Holoceno; e uma segunda fase, de $6,7 \mathrm{ka}$ até os dias atuais, já no Holoceno, a qual é controlada pelo balanço sedimentar negativo. Esse balanço negativo da distribuição de sedimentos é contribuído por; (i) uma falta de fontes de sedimentos atual, porque ficam aprisionados nas lagoas costeiras do RS ou nos promontórios da costa do Uruguai e; (ii) pela retirada de sedimentos pela deriva litorânea, que ocorre principalmente ao sul das projeçóes da linha de costa do RS, local em que a praia do Hermenegildo se encontra. Esses sedimentos removidos pela deriva litorânea tendem a se acumular nas reentrâncias da linha de costa localizadas mais ao norte, como, por exemplo, no balneário Cassino (Limaet al., op. cit.).

Atualmente, é consenso na comunidade científica que a praia do Hermenegildo está em erosão costeira. Evidências são expostas desde perfis praiais diagnosticando perdas de volume da praia (Calliari et al., 1998; Machado \& Calliari, 2011), passando por evidências demonstradas com a variaçáo da linha de costa (Toldo Jr. et al., 2005; Esteves et al., 2008) ou encontradas em imagens de satélite e fotos aéreas 


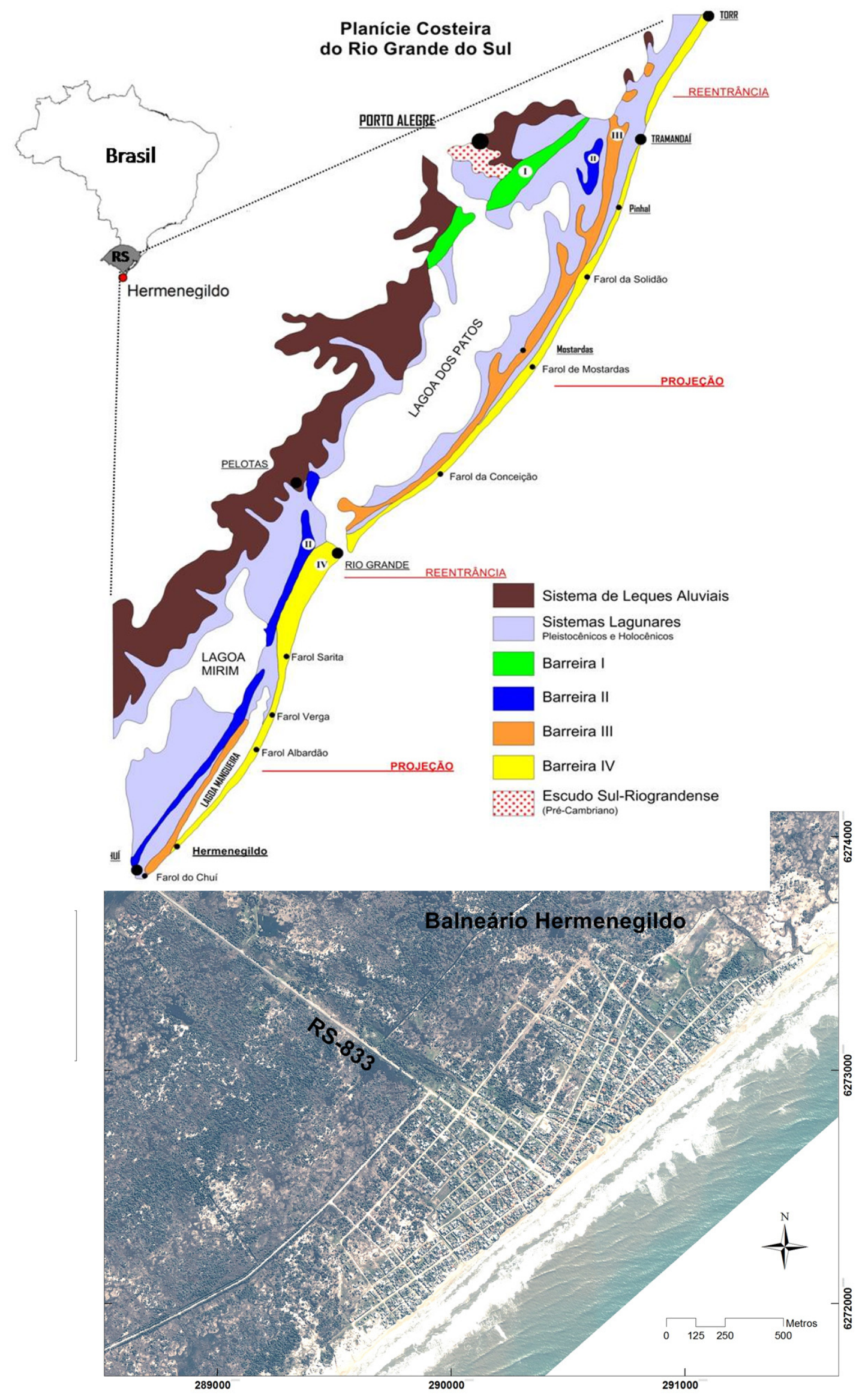

Figura 1. Localização da área de estudo.

Figure 1. Study area. 
(Koerner, 2009; Albuquerque, 2013) e mesmo indicaçóes apresentadas pela destruição de casas da orla do balneário (Esteves et al., 1999b; Esteves \& Santos, 2001; Esteves et al., 2003). A praia do Hermenegildo também apresenta dunas escarpadas, metais pesados e turfas aflorando na face praial (Calliari et al., 1998; Dillenburg et al., 2004a; Dillenburg et al., 2004b).

Quanto às taxas de erosão anuais para o balneário Hermenegildo, diversos valores foram encontrados, dependendo do ano e período de análise e da metodologia utilizada. Toldo Jr. et al., (2005) traçaram uma linha de água de 1999 para o litoral do Rio Grande do Sul com um GPS cinemático. Esses autores compararam as linhas coletadas em seu trabalho com a linha apresentada em cartas náuticas de 1975 e identificaram um recuo que excede 100 metros nas áreas mais críticas. Baseado nesse estudo, os autores sugeriram uma taxa de recuo de $4 \mathrm{~m} /$ ano para a praia do Hermenegildo. Também utilizando um GPS cinemático, ao comparar 6 linhas de costa obtidas entre 1999 e 2006, Esteves et al., (2008) calcularam uma taxa de retraçáo da linha de costa de $3,4 \mathrm{~m} /$ ano. Ao comparar perfis de praia no mesmo ponto obtidos em 1991 e 1996, Tozzi (1999) encontrou pequena variação na posição da linha de praia, mas significativas mudanças no volume sedimentar subaéreo da ordem de $50 \mathrm{~m}^{3} / \mathrm{m}$ com uma retração de 4 metros das dunas frontais, obtendo uma taxa de retraçáo costeira de $0.5 \mathrm{~m} /$ ano na praia do Hermenegildo. Com um maior período de abrangência, Machado \& Calliari (2011), analisando diferenças entre perfis de praia levantados em julho de 2011 e março de 1996, obtidos no mesmo ponto, encontraram uma taxa de erosão de 3,6 m/ano, com um recuo da linha de costa, ao nível do mar, de $55 \mathrm{~m}$, apresentando perda de volume da ordem de $130.46 \mathrm{~m}^{3} / \mathrm{m}$ de sedimentos. Ao comparar fotos aéreas e imagens de satélite com dados de RTK-GPS, Koerner (2009) estimou uma retração de aproximadamente $1,22 \mathrm{~m} /$ ano entre 1964 e 2009. Utilizando uma combinação de metodologias envolvendo imagens de satélite, fotografias aéreas, dados de GPS-RTK e técnicas de geoprocessamento, Albuquerque (2013) encontrou uma taxa média de $1,68 \mathrm{~m} /$ ano de erosão entre 1947 e 2012. Este autor também registrou os maiores picos de erosão entre 1996 e 2000 (6,29m/ano) e entre 2005 e 2006 (5,25 m/ano), que coincidem com eventos de El Niño e anomalias na Temperatura da Superfície do Mar (TSM) ocorridas nestes mesmos períodos.

O processo de urbanização do balneário Hermenegildo iniciou no final do século XIX sobre uma área de extensas dunas existentes na região, já próximo à linha de costa. Esse local foi escolhido por ser o primeiro acesso à praia ao sul da Lagoa Mangueira, cuja ocupação já se iniciou com o motivo de recreação e veraneio. Inicialmente, o problema dos proprietários era o soterramento de suas casas pela areia durante o inverno (Vidal, 2008). O desenvolvimento do balneário só foi intensificado na década de 1970, em virtude da facilidade de acesso após fixação das dunas no local (Esteves, et al., 2000; Koerner, 2009). Desde então, essa urbanização vem ocorrendo de forma mais acelerada, com adensamento das construções próximas à linha de costa, sendo ainda o principal atrativo do local a faixa de praia durante o período de veraneio (Esteves et al., 2003). Fazendo uma análise histórica das fotos aéreas de 1947 e 1964 e da imagem de satélite de 2005, Koerner (2009) percebeu que a ocupação do balneário Hermenegildo já se iniciou paralela à costa, mantendo esse padrão até os dias atuais. Com essas imagens, também foi diagnosticada a fixação e retirada das dunas, o que facilitou o crescimento urbano.

Devido ao processo de urbanizaçáo e ao processo erosivo descritos acima, atualmente, a orla do balneário Hermenegildo encontra-se bastante estruturada com variadas formas de proteção costeira (Esteves et al., 1999a; Teixeira, 2007; Koerner \& Oliveira, 2010). Essas estruturas podem conter desde pneus, entulhos, estacas e muros de madeira, a estruturas mais robustas, como enrocamentos, blocos e muros de concreto. A distribuição de tais estruturas parece ser diferenciada ao longo da orla (Fig. 2), predominando as estruturas mais robustas na parte central da orla do balneário (próximo à Iemanjá). Estruturas mais simples, como estacas e muros de madeira, são maioria no trecho sul da orla do balneário, enquanto o trecho norte parece ser o mais preservado, onde predominam dunas frontais (Koerner \& Oliveira, 2010).

\section{MATERIAL E MÉTODOS}

Primeiramente, foi realizado um reconhecimento da área, visando o planejamento dos pontos de amostragem. As mediçóes in loco foram efetuadas posteriormente, nos dias 10 e 11 de outubro de 2009, as quais consistiram basicamente no levantamento de coordenadas geodésicas com alta precisão na área de estudo. Foram medidas, ou mapeadas, as seguintes linhas de referência: toda a linha limite das escarpas e estruturas de contenção do balneário e da base das dunas frontais em uma extensão de aproximadamente 5 $\mathrm{km}$ de costa; a linha da água de máxima maré (High Water Line) nesta mesma extensão; 22 perfis topográficos junto às ruas do balneário que são perpendiculares à praia, para averiguar as diferenças morfológicas das escarpas encontradas em diferentes segmentos do balneário. Esses dados foram corroborados por outras ferramentas de análise, tais como imagens aéreas, mosaicos de fotografias convencionais e identificação das estruturas de contenção, além da própria revisão bibliográfica.

\subsection{Aquisiçáo, precisáo e plotagem dos dados}

O método de obtençáo de dados utilizado foi o de posicionamento relativo cinemático em tempo real (Real Time Kinematic - RTK) de levantamento de dados pelo Sistema de Posicionamento por Satélites (GPS). Esse método consiste em posicionar um receptor GPS em um ponto fixo de coordenadas conhecidas (Fig. 3A) e outro receptor móvel no ponto no qual se deseja determinar as suas coordenadas (Fig. 3B), com um tempo de coleta e rastreio mínimos.

$\mathrm{O}$ receptor utilizado foi um GPS geodésico marca SOUTH, modelo 82, capaz de receber as frequências L1 e L2 com 5 canais paralelos e independentes para a recepção dos sinais de satélite. Todos os pontos do caminhamento foram registrados pelo modo stop-and-go, que consiste em parar no ponto e salvar as suas coordenadas. A antena de estação base permaneceu fixa no ponto de coordenadas conhecidas de uma Referência de Nível (RN). Essa RN pertence à Rede de Nivelamento Brasileira, construída 


\section{A) extremo norte}

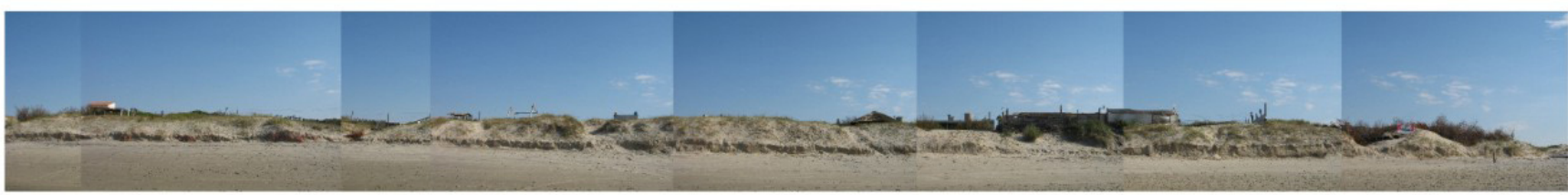

B) norte

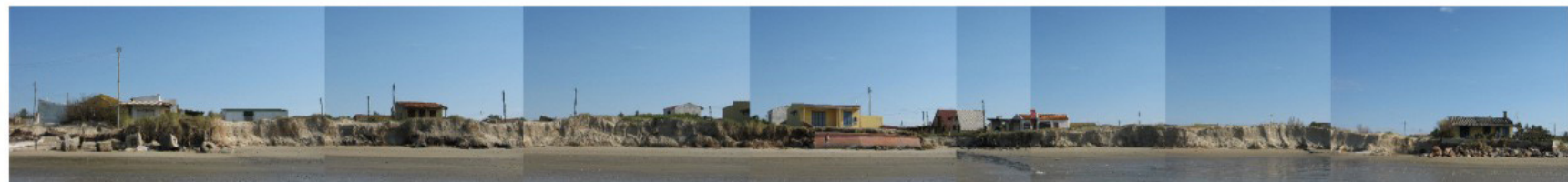

C) centro norte

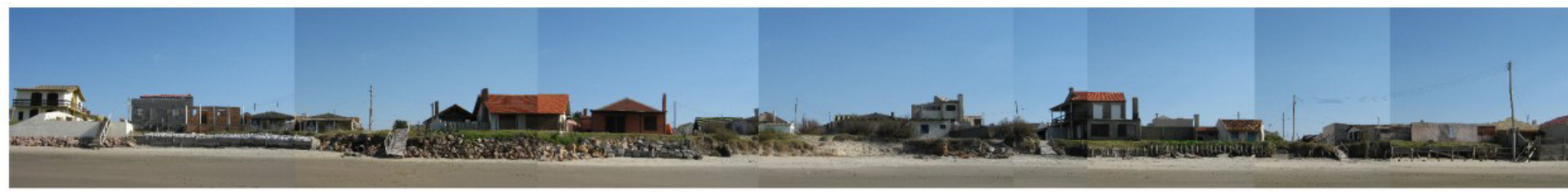

D) centro - lemanjá

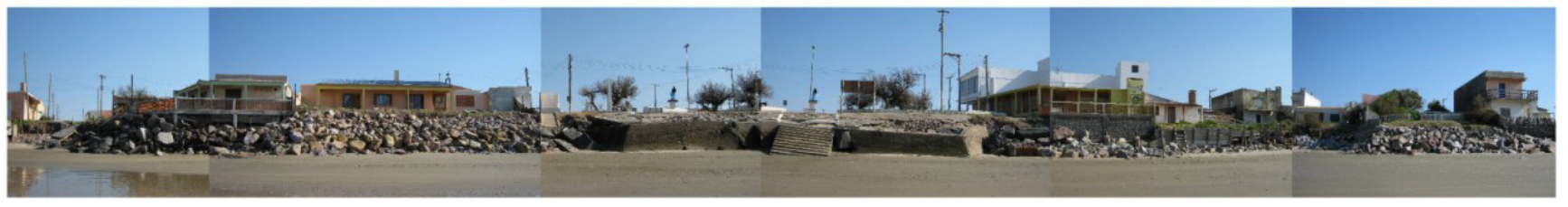

E) centro sul

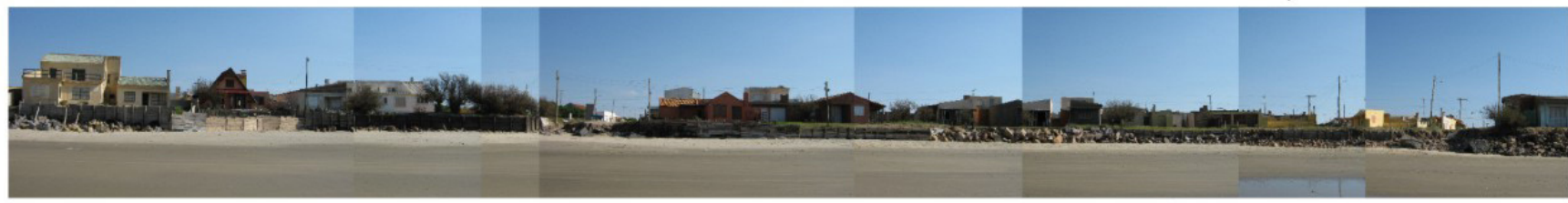

F) sul

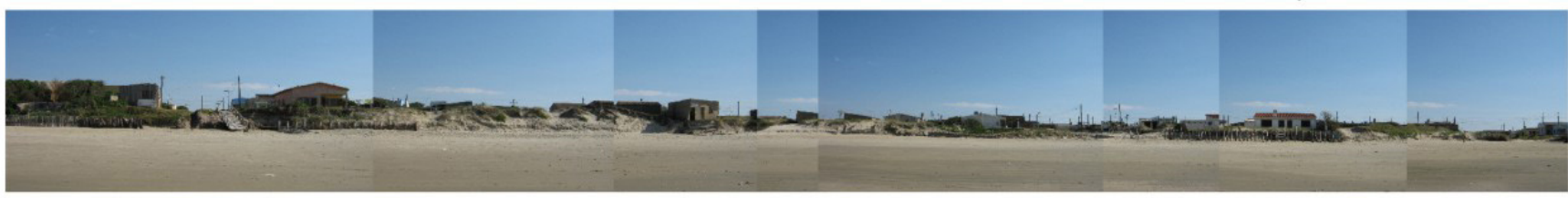

G) extremo sul

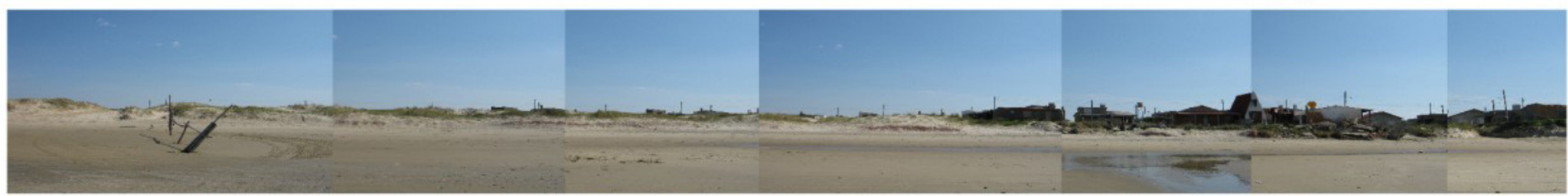

Figura 2. Mosaico de fotos de diferentes trechos da orla do balneário do Hermenegildo no dia 28 de agosto de 2009. (fotos e mosaico: Ulisses Rocha de Oliveira).

Figure 2. Mosaic made of pictures from different parts of the Hermenegildo's beach seafront on August 28, 2009. (photos and mosaic: Ulisses Rocha de Oliveira). 


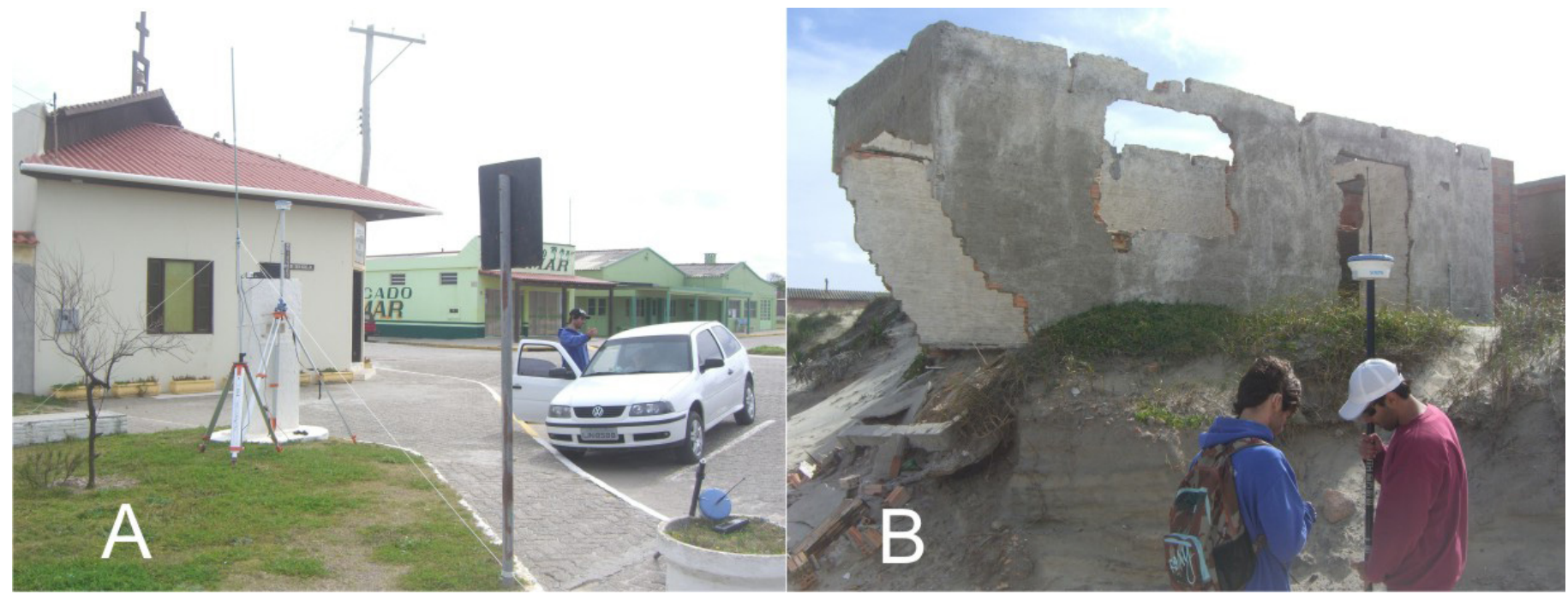

Figura 3. Método de posicionamento do GPS, (A) com um receptor em um ponto fixo sobre a Referência de Nível RN1969A próximo à estátua de Iemanjá e $(\mathrm{B})$ um receptor móvel utilizado para mapeamento dos pontos de interesse.

Figure 3. Method of GPS positioning, (A) with a receiver at a fixed point on the Reference Level RN1969A near the statue of Iemanja and (B) a mobile receiver used for mapping the points of interest.

pelo Instituto Brasileiro de Geografia e Estatística (IBGE), identificada pela RN1969A, materializada por um marco de concreto (antigo monumento) localizado próximo à estátua de Iemanjá e da igreja católica (Fig. 3A), situada ao final da RS-833, no balneário Hermenegildo, cuja altitude ortométrica é de 4,5557 m.

Os dados obtidos foram organizados em uma tabela com cada ponto adquirido e as suas respectivas coordenadas $\mathrm{X}, \mathrm{Y}$ baseadas no datum WGS84, zona 22 Sul, e projetadas em UTM (Universal Transversa de Mercator); e coordenadas de altitude $\mathrm{Z}$ ('h') que correspondem à altitude do ponto amostrado em relaçáo ao elipsóide WGS84. Essas coordenadas de altitude Z (geométricas ' $h$ ') foram, então, convertidas para altitudes reais (ortométricas ' $\mathrm{H}$ ') com relação ao modelo do geóide local. Essa conversão foi realizada através de um modelo de ondulação geoidal ('N') conforme metodologia descrita em Corseuil \& Robaina (2003). Neste trabalho, o modelo foi calculado com base nos pontos das Referências de Nível RN1969A, RN1969B e RN1969N, sendo os dois primeiros localizados no balneário Hermenegildo, e o último, no município do Chuí.

Tendo a ondulação geoidal ('N') calculada, basta, então, subtrair a ela o valor da altitude geométrica ('h') que se obtém, então, a altitude ortométrica ('H') real com a seguinte equação: $\mathrm{H}=\mathrm{h}-\mathrm{N}$. Esses cálculos do modelo geoidal e da equação da ondulação geoidal foram realizados com software de programaçáo através de rotinas computacionais (Corseuil \& Robaina, op.cit.).

Com o fim de fazer uma averiguaçáo do erro das coordenadas ortométricas calculadas e do modelo da ondulação geoidal, foi usado um nível topográfico para fazer o levantamento dos pontos de controle. A precisão esperada para os dados que foram coletados com uma taxa da diluição da precisão pela distribuição espacial dos satélites (PDOP) menor do que 5 é de 3 a 5 centímetros. Sabendo disso, quando os valores do PDOP em um ponto estavam sendo informados pela controladora como acima de 5, estes eram recusados. O cálculo da precisão das altitudes ortométricas calculadas a partir dos pontos levantados com o GPS foi realizado comparando estes pontos com os pontos obtidos com o nível, que indica os pontos ortométricos reais com maior precisão. A Figura 4 mostra os perfis realizados pelo nível topográfico e pelo GPS traçados em um mesmo trajeto, partindo da RN-1969A até a RN-1969B, para identificação do erro amostral do RTK-GPS.

O coeficiente de correlaçáo (r) entre esses dois perfis foi de 0,99 , e a diferença entre os valores quadráticos médios (RMS) dos diferentes perfis foi de 0,11488 metros.

Com os dados brutos já processados, eles foram, então, plotados e trabalhados sobre uma imagem de satélite Quickbird $^{\text {TM }}$ de 2005, utilizando o software ArcGIS 9.3.1 ${ }^{\circledR}$. Para a representação final dos perfis transversais, como estes estavam em planos de coordenadas geodésicas, as distâncias entre um ponto e outro foram medidas com a ferramenta measure distance do programa, e estas distâncias foram anexadas em um novo campo da tabela de atributos dos dados dos perfis. Para melhor entender a espacialização dos dados adquiridos, estes foram divididos em: linhas de referência paralelas à costa e perfis perpendiculares à costa.

\subsection{Linhas de referência paralelas à costa: linhas de dunas, linha de dunas interpolada e linha d'água}

As feiçóes indicadoras da linha de dunas consideradas para este trabalho foram divididas em duas partes: Em frente à zona urbanizada (orla do balneário), há áreas onde já não existem dunas, e sim diversas formas de estruturas de contençáo. Nessa parte, a linha foi traçada praticamente no limite das estruturas de contençáo com a praia. No restante (também chamada de linha de dunas neste trabalho), foi mapeada a base das dunas frontais. 


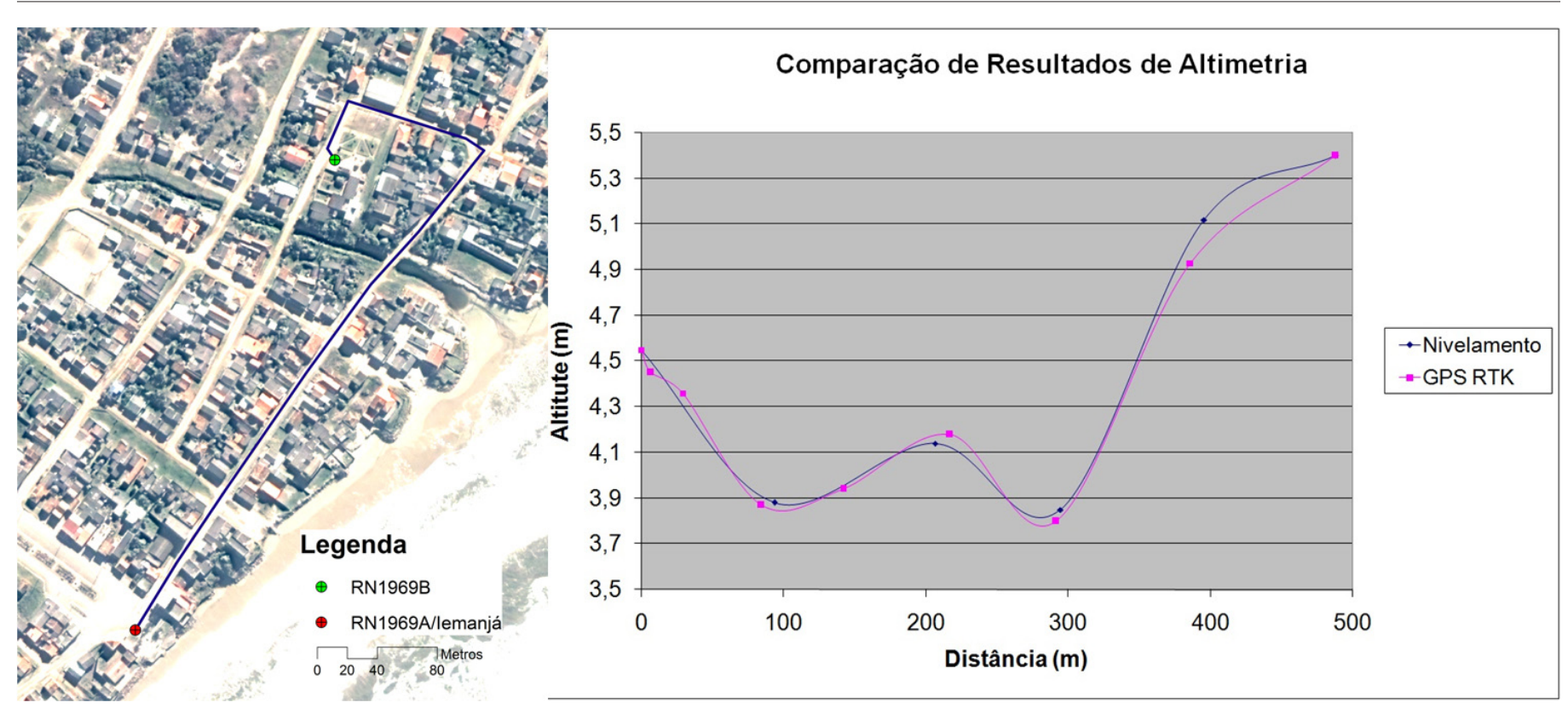

Figura 4. Gráfico da comparaçáo entre os resultados de altimetria obtidos pelo nível (controle) e pelo GPS RTK (direita) realizados em um caminho entre as referências de nível RN1969A e RN1969B (esquerda).

Figure 4. Graph comparing the altimetry results obtained by a topographic level (control) and by GPS RTK (right) in the some way from the reference level RN1969A to RN1969B (left).

Para analisar se o setor central do balneário está mais projetado sobre o pós-praia do que as periferias, foram medidos em campo, com o uso de um GPS de alta precisão, três segmentos: (i) as Dunas do SUL, que são as dunas frontais ao sul do balneário (partindo da rua de acesso à praia mais meridional no balneário até aproximadamente $1,5 \mathrm{~km}$ para o sul); (ii) a Orla Urbanizada, que é a porção frontal ao balneário (onde há estruturas de contenção e algumas dunas) e; (iii) as Dunas do NORTE, ou seja, as dunas frontais ao norte do balneário (da rua de acesso à praia mais setentrional do balneário até cerca de 1,5 km para o norte) (Fig. 5).

Posteriormente, foi realizada uma regressão linear com os pontos GPS que demarcam as linhas das dunas frontais ao sul e ao norte do balneário, de modo que se obteve uma linha que representa uma "reta média" desses pontos. Essas linhas resultantes da regressão linear dos pontos GPS foram interligadas por uma linha reta unindo os dois trechos onde ocorrem somente dunas frontais (Fig. 6). Essa linha reta será chamada de "Linha de dunas interpolada". Considerando que a costa do Rio Grande do Sul possui uma característica de se apresentar como uma linha aproximadamente retilínea (em uma escala de até poucas dezenas de quilômetros), essa linha interpolada seria a posição esperada da linha de costa para a orla urbanizada. Em outras palavras, tal linha interpolada representaria a base das dunas frontais em frente ao balneário, caso não houvesse interferência humana, e a fixação da costa com estruturas de contenção.

O objetivo dessa Linha de Dunas Interpolada é perceber se existe uma diferença entre a "linha de dunas" na Orla Urbanizada em frente ao balneário, onde praticamente já não há dunas, e sim várias formas de estruturas de contenção, e a Linha de Dunas em áreas com nenhuma ou muito pouca interferência antrópica, onde há livre mobilidade do sedimento em resposta às alteraçóes dos processos costeiros.

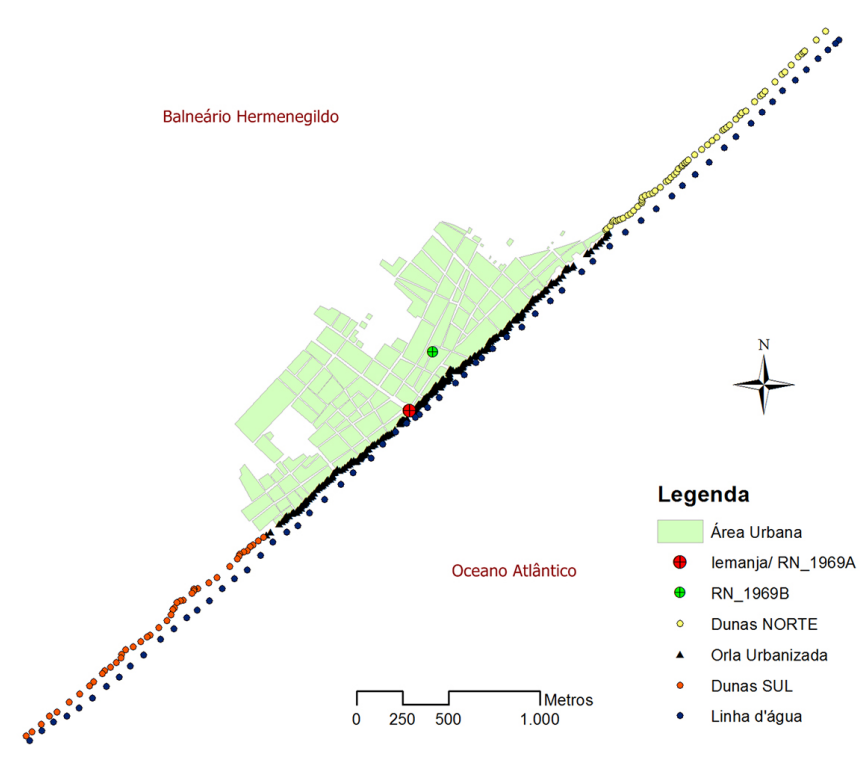

Figura 5. Pontos obtidos em campo com GPS RTK relativos às linhas de referência paralelas à costa.

Figure 5. Points obtained in the field with GPS RTK related to the reference lines parallel to the coast: waterline, shorelines from the base of the foredunes from north and south, and the shoreline from urbanized coast. 


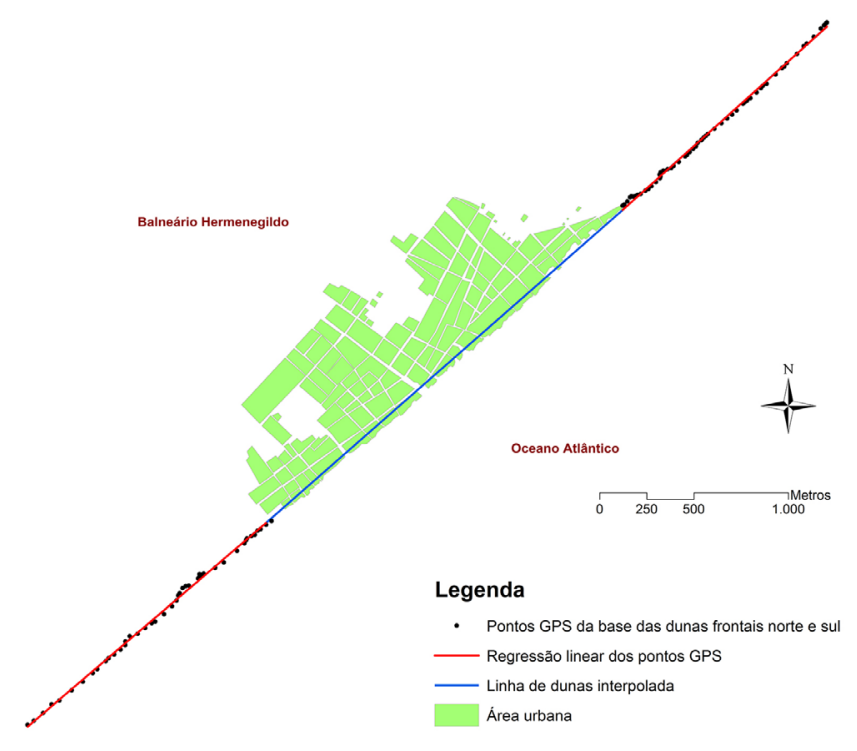

Figura 6. Pontos obtidos da base das dunas frontais nas áreas adjacentes ao balneário do Hermenegildo e a linha interligando as dunas do norte e sul, denominada "linha de dunas interpolada".

Figure 6. Points obtained from the base of foredunes in adjacent areas to the Hermenegildo urban coast and the line connecting north dunes to the south dunes, called "interpolated line of dunes".

Já a Linha da Água mapeada foi a linha indicativa da máxima maré alta (High WaterLine) (Fig. 5). Essa linha é indicada pelo limite máximo do varrido da praia no dia. De todas as linhas de água, esta é a que possui menor variação durante o dia, pois é a marca deixada ali no pico de máxima maré. Mas, ainda assim, esta linha está suscetível a grandes variaçóes dentro de poucos dias, dependendo tanto da maré astronômica como da maré meteorológica. No dia em que essa linha foi mapeada, dia 10 de outubro de 2009, havia um intenso vento nordeste $\left(46^{\circ}\right)$, de aproximadamente $9,5 \mathrm{~m} / \mathrm{s}$, segundo estação meteorológica do Chuí (INMET), que talvez, por efeito de Ekman sobre a água do mar, pudesse estar baixando esta linha de modo que ficasse mais afastada da costa do que se estivesse apenas sob a ação da maré astronômica. O máximo pico de maré astronômica naquele dia foi de $0,7 \mathrm{~m}$ às $11 \mathrm{~h} 56 \mathrm{~min}$ (fonte: Praticagem do Rio Grande).

\subsection{Perfis topográficos transversais à costa}

Com o objetivo de averiguar se há diferenças na morfologia das escarpas e da praia entre o setor central e as periferias da orla urbanizada (corroborando com a hipótese de que a porção central do balneário está mais à frente do que a linha de dunas interpolada), foram traçados 22 perfis topográficos perpendiculares à costa em toda a orla urbanizada, medindose todas as ruas transversais do balneário que dão acesso à praia (Fig. 7). Destes, foram escolhidos 6 perfis, cujas diferenças foram mais representativas para discussão e apresentação: dois na parte central do balneário próximo à estátua de Iemanjá, dois em áreas a sul e a norte, mas ainda na porção central (periféricos), e dois perfis nas extremidades da orla urbanizada (últimas ruas de acesso à praia, tanto ao norte como ao sul). Todos os perfis partiram da Avenida Cruzeiro do Sul, limite transversal da orla estabelecido neste trabalho, seguindo pela rua em direção à praia, passando pela escarpa medindo o seu desnível, e seguindo pela praia até a linha da água.

\section{RESULTADOS}

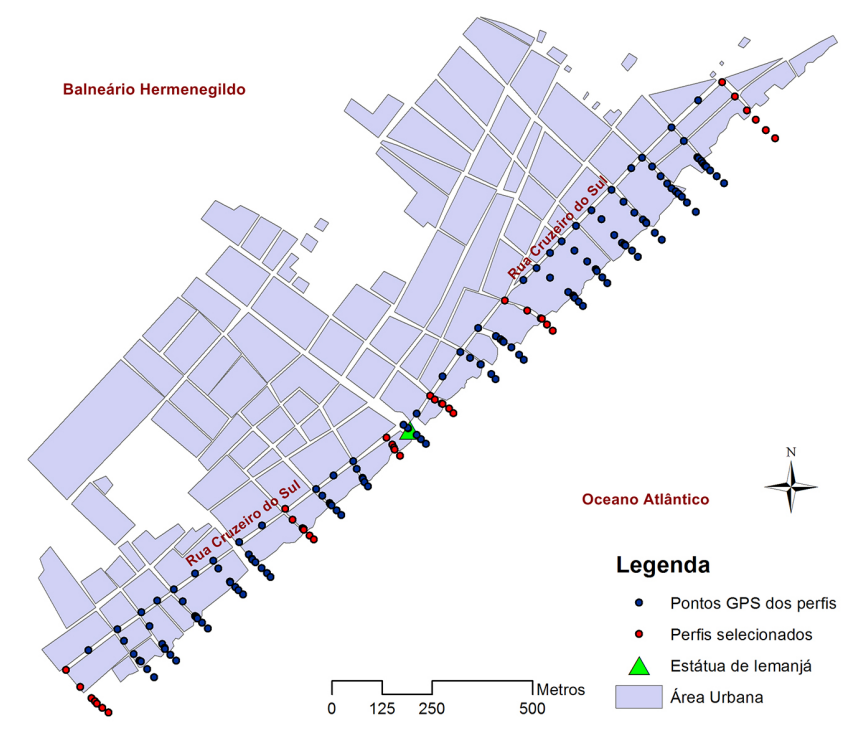

Figura 7. Perfis topográficos perpendiculares à costa. Os pontos foram mapeados desde a Rua Cruzeiro do Sul pelas ruas do balneário que dão acesso à praia, passando pela escarpa e seguindo pela praia até a linha de água.

Figure 7. Topographic profiles perpendicular to shore. The points were mapped from the Cruzeiro do Sul Street through the streets of the resort that give access to the beach passing by the slope and the beach toward the water line.

As linhas de dunas nos setores denominados Dunas do Norte e Dunas do Sul se apresentaram com uma conformação relativamente retilínea e próxima do que se espera de um ambiente natural de praias e dunas frontais para o local, onde predominam praias bastante retilíneas ou alongadas em planta, exceto pela presença dos canais sangradouros, que geram pequenas reentrâncias. Já o setor da Orla Urbanizada apresenta uma linha do limite superior da praia bastante irregular, devido às várias formas de estruturas de contenção que compóem este trecho, formando pequenas enseadas e promontórios conforme alternam os terrenos desprovidos de estruturas ou com estruturas mais simples ou aqueles protegidos com estruturas como enrocamento e/ou muros de concreto (detalhe da Fig. 8).

Comparando o posicionamento do limite superior da praia (linhas da base das escarpas e dunas) entre os diferentes setores, percebe-se que as estruturas de contenção estão cumprindo seu papel de conter o avanço marinho no local. A 
porção central da orla urbanizada do balneário Hermenegildo encontra-se, em 2009, numa posição mais próxima da linha da água do que as dunas frontais adjacentes, estando atualmente sobre a pós-praia (Fig. 8).

Visualiza-se, a partir da figura 8, que existe uma área de avanço de toda a orla urbanizada sobre linha de dunas interpolada. Essa área de contenção foi calculada para o ano de 2009 (período da medição) em aproximadamente 54.100 $\mathrm{m}^{2}$. A maior distância entre a linha da orla urbanizada e a linha de dunas interpolada foi calculada em 45,3 metros (Fig. 8, 'M'). Dessa forma, percebe-se que, se as estruturas de contenção não existissem no local, provavelmente a linha das dunas na parte central estaria a 45 metros mais para o interior do continente do que está atualmente. Em outras palavras, pode-se dizer que $54.100 \mathrm{~m}^{2}$ da orla que hoje está urbanizada seriam área de praia.

Também é interessante observar na figura 8 que, mesmo estando na zona urbanizada, as desembocaduras dos canais sangradouros tendem a acompanhar a linha de dunas interpolada. Junto aos sangradouros, não existem estruturas de contenção, permitindo, assim, o deslocamento horizontal da linha de costa em direçáo ao continente com maior mobilidade, fato que também ocorre nas áreas não urbanizadas ao norte e ao sul do balneário.

Outro aspecto relevante é que, em frente ao setor central do balneário, a linha da água apresentou uma deflação em

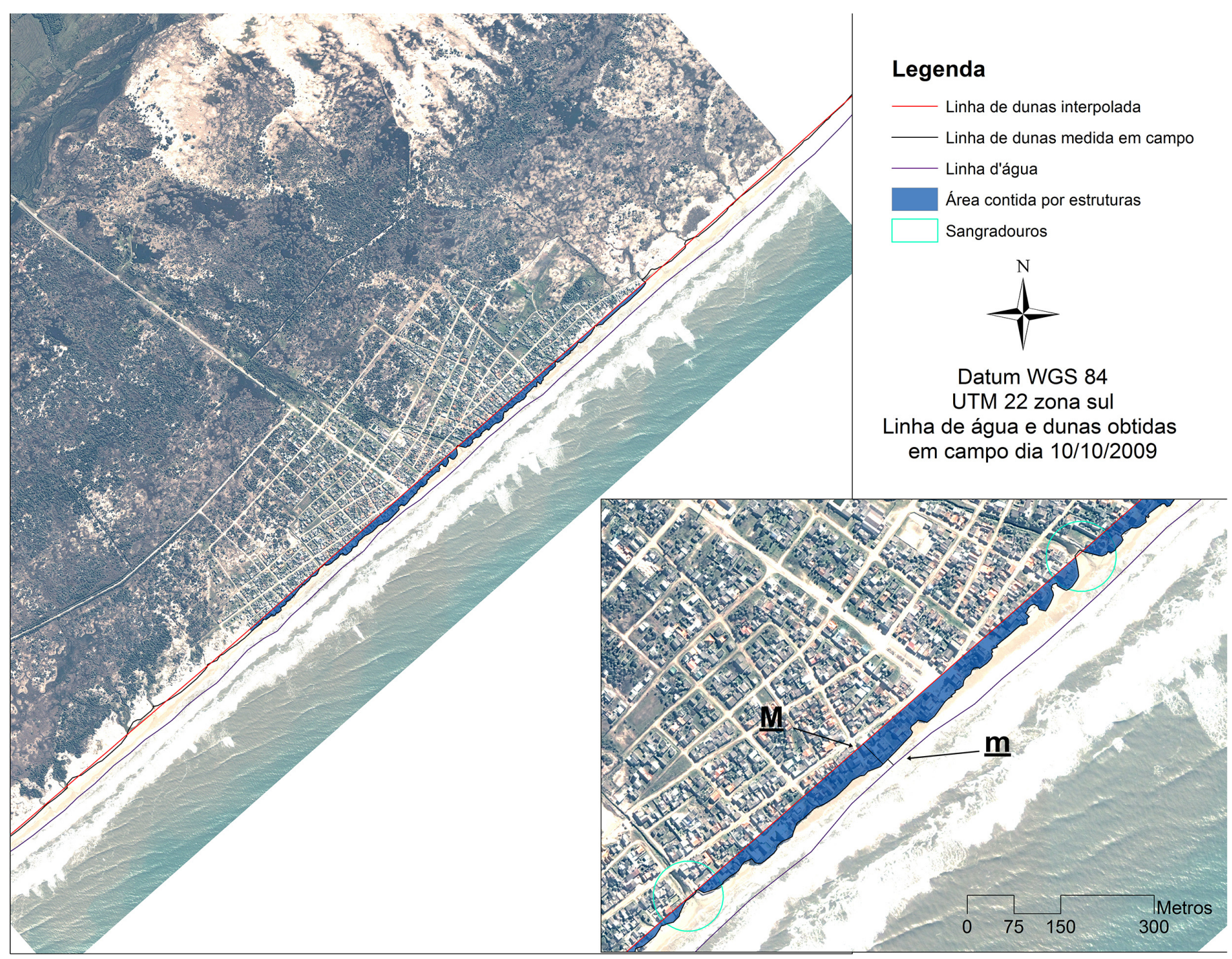

Figura 8. Imagens do balneário do Hermenegildo mostrando a linha de água, a linha das dunas e a linha de dunas interpolada, que liga as linhas de dunas do norte e sul (imagem maior). No detalhe, é possível notar as distâncias entre a linha de dunas atual e a linha de dunas interpolada $(\underline{\mathrm{M}})$, e também entre a linha de dunas e a linha da água $(\underline{\mathrm{m}})$. Nos círculos, estão destacados os sangradouros e como estes são próximos à linha de dunas calculada.

Figure 8. Images from the Hermenegildo beach village showing the water line, the boundary line of contention structures and dunes, and interpolated dune line that connects the lines of dunes of north and south (larger image). In detail is possible to note the distances between the current dune line and interpolated dune line $(\underline{M})$, and also between the dune line and water line $(\underline{m})$. In the circles are highlighted the washouts and how these are close to the interpolated dune line. 
forma côncava em planta (Fig. 8, 'm’'). A menor distância da costa em relação à linha d'água do dia 10 de outubro foi de aproximados 12,5 metros neste local, relacionado à projeçáo das estruturas de contenção e à concavidade da linha d'água. Durante a realização do presente estudo, este setor da praia apresentou menor estoque sedimentar subaéreo do que nas periferias. Segundo observaçóes e relatos dos moradores locais, tal concavidade é comum nos meses mais próximos ao inverno, inclusive fazendo com que a praia emersa desapareça durante vários dias e que a posição desta concavidade possa variar sua posição, mas sempre se mantendo na área de abrangência das estruturas de contenção.

A figura 9 apresenta os resultados dos perfis topográficos dos diferentes setores da Orla Urbanizada. É importante esclarecer que nesta figura as escalas verticais dos gráficos estão padronizadas em 6 metros de altitude, e as horizontais se alteram, sendo 80 metros, 150 metros e 200 metros de distância nos perfis centrais, periféricos (norte e sul) e extremos respectivamente, com o fim de facilitar a visualização.
Observa-se na figura 9 que existem escarpas bem marcadas nos perfis realizados na orla urbanizada (perfis centrais, norte e sul) e que os perfis dos extremos norte e sul não apresentam escarpa, com uma topografia variando suavemente.

O topo da escarpa é de 4 metros para todos os perfis da orla urbanizada, e todas as escarpas se apresentaram bastante íngremes com pendente quase vertical. Entretanto, esses perfis se diferenciam em alguns pontos: os perfis centrais apresentam uma praia plana, enquanto os perfis do norte e sul apresentam uma praia com uma declividade um pouco mais suave. Além disso, pode-se ver, na figura 9, que, nos perfis centrais, a base da escarpa (limite superior da praia) se encontra mais próxima da linha da água (ponto zero) do que nos outros perfis, com destaque para o perfil do centro sul. Tal aspecto pode estar associado à concavidade da linha d'água no período. A continuação do processo erosivo e/ ou migraçáo da concavidade pode expandir as escarpas para outros segmentos do balneário.

\section{DISCUSSÃO}

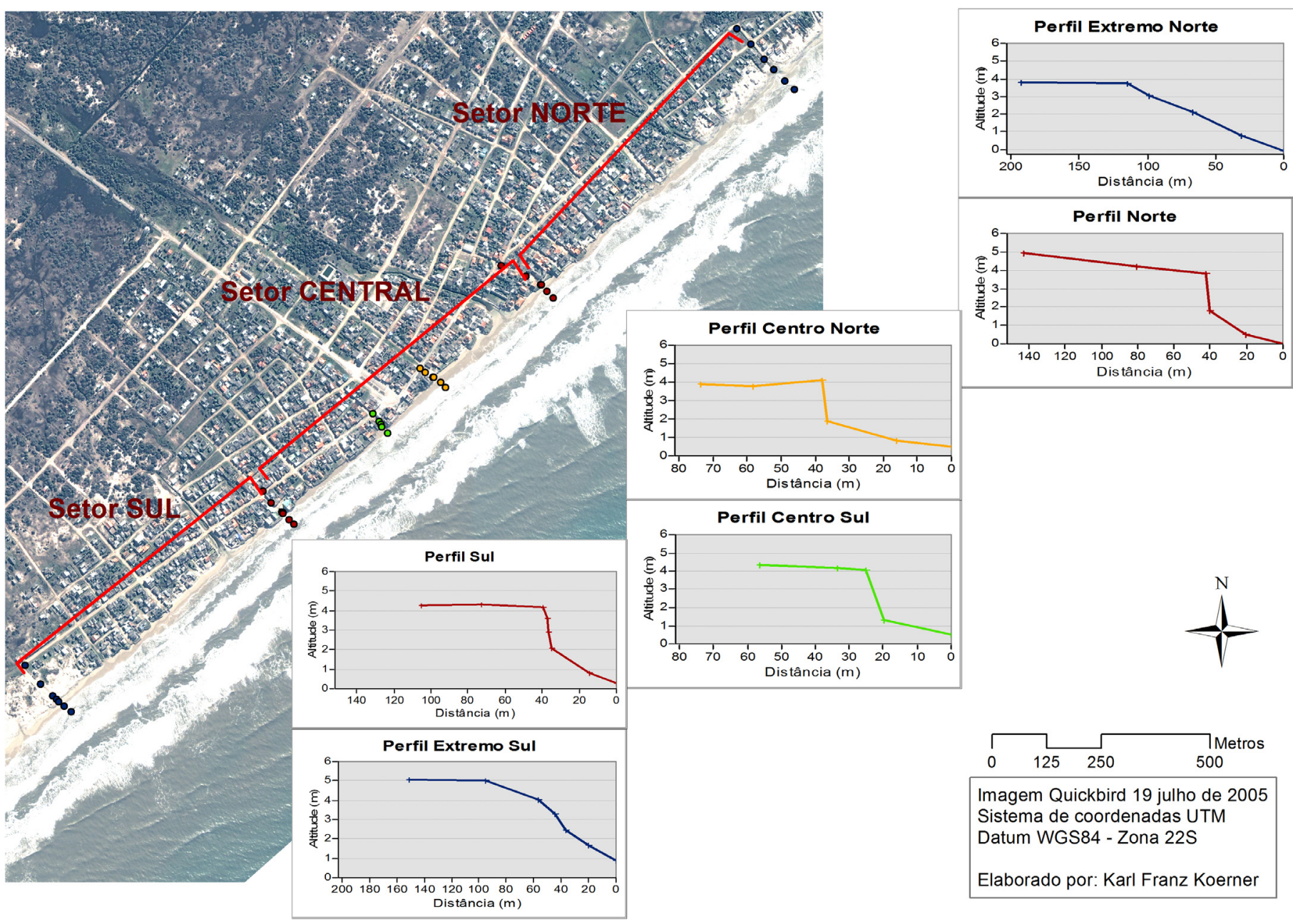

Figura 9. Imagem do balneário do Hermenegildo com os gráficos que representam os perfis topográficos selecionados para a análise: centrais, periféricos e extremos, e suas respectivas localizaçóes.

Figure 9. Image of the Hermenegildo beach village showing the graphs of the topographic profiles selected for analysis: central, periphery and extremes, and their respective locations. 
Esta pesquisa apresentou pelo menos dois resultados bastante interessantes: (i) uma evidência sólida de que a praia do Hermenegildo está em erosão e, ao mesmo tempo, de que as estruturas de contenção - mesmo que realizadas de modo individual pelos moradores, muitas vezes sem conhecimento técnico adequado - vêm contendo, pelo menos parcialmente, a erosão da orla urbanizada e; (ii) que há evidências de maior exposição do setor central aos eventos erosivos ao se apresentar mais projetado para o mar se comparado às periferias, e que isso gera impactos na morfologia da praia, tendo em vista as diferenças morfológicas da praia e escarpa, além da deflação da linha d'água nesse setor.

Essas características podem ser corroboradas com a pesquisa de Koerner \& Oliveira (2010), que analisaram o comportamento e as alteraçóes ocorridas nas estruturas de contençáo nos últimos 10 anos e notaram uma tendência de aumento do número de casas com obras de contenção, uma vez que o número de casas com estruturas de proteção aumentou, de 1999 a 2009, de 67 para 84 casas protegidas. Outro fato interessante é que, em uma análise da distribuição das estruturas de contenção entre os setores, estes autores viram que, no setor central, $89 \%$ das casas estáo com alguma forma de proteção, contra os $63 \%$ de casas protegidas no setor sul e apenas $29 \%$ no setor norte do balneário, com porcentagens crescentes em todos os segmentos do balneário. Além disso, também se percebeu o aumento da robustez das obras de proteção das casas com o passar dos anos, com substituiçáo de diversos tipos de estruturas de contenção pelo tipo enrocamento, a qual parece se mostrar eficiente, pois, além de combater o varrido das ondas, se adapta à alteração morfológica do substrato arenoso.

Segundo Koerner (2009), a ocupação mais antiga na parte central é responsável por uma maior densidade urbana neste setor do que nas periferias, onde os perfis são mais largos e as ruas paralelas à praia se afastam da linha de costa conforme a ocupação foi mais recente, dando ao balneário essa forma "curiosa" de seta apontando para o mar (observar ruas na Fig. 1). Por ter uma ocupação mais antiga, os proprietários das casas desse setor vêm protegendo-as há mais tempo, o que faz com que esse trecho apresente estruturas mais robustas, como enrocamentos e muros de concreto e com maior densidade. Essa maior concentração de enrocamentos no setor central pode explicar o porquê de este setor estar mais avançado sobre a pós-praia do que as periferias, como aponta o presente estudo.

Além disso, parece haver, nos últimos anos, uma espécie de reação em cadeia por parte dos proprietários. Inicialmente, apenas alguns proprietários colocavam estruturas reforçadas para o propósito de conter a erosão e proteger seu patrimônio. No entanto, observava-se que, mesmo com a contençáo na porção frontal, o mar poderia avançar pela lateral, sobretudo pelo limite sul do terreno (Esteves et al., 2003). Da mesma forma, quando um determinado proprietário protegia sua casa, via-se claramente que a casa do vizinho que não a protegia passava a ficar muito mais vulnerável. Em abril de 1999, o maior evento erosivo registrado na história do balneário devastou sua orla. Segundo Esteves et al., (1999b) e Esteves \& Santos (2001), 20\% das casas que havia à beiramar foram total ou parcialmente destruídas. É importante ressaltar que, naquele momento, as estruturas de contenção eram menos robustas que as de hoje e apresentavam-se bastante descontínuas. A partir deste evento, houve uma mobilizaçáo dos moradores, buscando o Poder Público e universidades para tentativa de soluçáo do problema. Até o presente momento, passados mais de 10 anos, náo houve ação efetiva do Estado sobre o problema (Koerner, 2012), mas sim um grande número de estudos sobre a temática e, efetivamente, um progressivo aumento da proteção das propriedades, partindo de contençóes pontuais para a disposição destas como uma longa e contínua estrutura em boa parte da orla, cuja ação partiu dos próprios moradores.

Esse conjunto de estruturas robustas e combinadas longitudinalmente está, atualmente, fixando a linha de costa como se fosse um grande muro de proteçáo (seawall). Da mesma forma, as interferências na linha de costa estão bastante semelhantes a essas obras de engenharia. Evidências de que muros de proteção deixam a praia mais plana e estreita já foram bastante documentadas na literatura (Dean, 1986; Kraus, 1988; Plant \& Griggs, 1992; Kraus \& McDougal, 1996). Entretanto, estes mesmos autores também averiguaram que, ao final de uma grande estrutura de proteção isolada na praia, ocorre a potencialização da erosão na praia adjacente. Por essa razão, os autores do presente estudo obtiveram dados das praias adjacentes em uma distância de $1,5 \mathrm{~km}$ do final da orla urbanizada, de modo que os efeitos de erosão causados pela proteçáo (que ocorrem até poucas dezenas de metros de distância da estrutura) fiquem diluídos na amostragem dos pontos.

Com este estudo não é possível avaliar se a erosão que ocorre em frente às estruturas de contenção é decorrente somente da erosão natural, ou se esta é potencializada pelas próprias estruturas. Kraus \& McDougal (1996) indicam que ocorre uma elevação do nível do lençol freático em frente aos muros de contenção e que pode ou não ocorrer uma retirada de sedimentos que são levantados em suspensão por causa do muro. Segundo os autores, o sedimento pode ser transportado transversalmente para a parte subaérea, ou entáo pode ser perdido do sistema sendo carregado por correntes longitudinais, dependendo do estado de equilíbrio da praia. A presença do embaiamento na linha d'água parece apontar para esta questão. No entanto, é interessante, em um próximo estudo, estender os perfis transversais até a zona de arrebentação e fazer um experimento com trapeação de sedimentos carregados na corrente longitudinal em eventos erosivos e de sobreelevação da maré e, sobretudo, a realização de um contínuo monitoramento do caso.

Contudo, é possível afirmar que a praia em frente à porção central do balneário já está bastante alterada pelas estruturas de contenção. Dentre as principais alteraçôes, estão: praia mais estreita, mais úmida, menor desenvolvimento da berma e ausência de dunas embrionárias e dunas frontais. Também está bastante claro que, durante períodos de maré alta, o mar atinge o limite superior da praia na porção central com facilidade, o que só ocorre nas áreas adjacentes ao balneário em períodos de significativa sobreelevação da maré.

Para o futuro próximo, com as taxas de erosão para o local podendo variar entre $0.5 \mathrm{~m} /$ ano (Tozzi, 1999) a $4 \mathrm{~m} /$ ano (Toldo Jr. et al., 2005), podendo superar $6 \mathrm{~m} / \mathrm{ano} \mathrm{em}$ alguns períodos (Albuquerque, 2013), é interessante pensar em alternativas de manejo de longo prazo para o balneário 
Hermenegildo, como, por exemplo, realizar um planejamento ambiental e ordenamento territorial considerando áreas mais afastadas da costa para o crescimento urbano (Koerner, 2012). No momento presente, casas defronte ao mar ainda vêm sendo destruídas conforme ocorrem grandes eventos de tempestade e estruturas de proteção colapsam. Também não se sabe ao certo como as estruturas de contenção do tipo enrocamento irão se comportar num ambiente de maior saliência da linha de costa do que a medida neste trabalho, qual seu comportamento com a presença de grandes ondas quebrando a poucos metros das referidas estruturas e frente a eventos semelhantes ou até de maior impacto no local do que o evento erosivo ocorrido em abril de 1999.

\section{CONCLUSÓES}

Analisando as diferenças morfológicas e da posição da linha de dunas encontradas entre a orla urbanizada e as dunas frontais nasáreas adjacentes, conclui-se que, atualmente, parte considerável da orla urbanizada do balneário Hermenegildo se encontra sobre a faixa de praia. Isso ocorre pelo fato de que as estruturas de contenção do balneário Hermenegildo vêm, mesmo que não totalmente, impedindo a migração horizontal da linha de costa em direçáo ao continente. Ou seja, essas estruturas estâo realmente fixando a linha de costa nesta área, embora muitas casas já tenham sido destruídas nos últimos 50 anos e substituídas por área de praia.

Especificamente, a linha de costa no setor central se encontra a quase 50 metros sobre a praia, à frente das dunas frontais adjacentes. Além disso, em frente a este mesmo setor, as estruturas de contenção geraram uma concavidade da linha de água, em planta, e também foram detectadas diferenças na morfologia da praia, com praia mais plana e estreita e escarpas bastante íngremes, se comparadas às praias adjacentes.

Cabe salientar que não é objetivo dos autores deste trabalho incentivar esse tipo de obra em outras orlas urbanizadas. Somente foi averiguado que as obras de proteção do Balneário Hermenegildo, sobretudo as do tipo enrocamento, vêm se mostrando eficientes ao conter localmente o processo erosivo, pelo menos no período analisado. No mesmo período, foram identificados significativos impactos para o ambiente praial, tendo menos área de praia tanto para dissipação de energia de ondas, como para a recreaçáo dos usuários da praia, enfim, uma completa supressão da orla natural, o que não se considera o mais adequado para o local. As estruturas podem gerar concavidades da linha de água, em planta, em frente ao setor central do balneário, interferindo no balanço sedimentar não só no plano horizontal como também gera um déficit vertical de sedimentos. Adicionalmente, detectamse maiores desníveis topográficos entre o limite superior da praia e a área urbana no setor central, onde há mais estruturas de contenção do que nas periferias, prejudicando o simples acesso à praia. Além disso, não se sabe até que ponto essas estruturas irão cumprir seu objetivo específico de proteção das casas e fixação da linha de costa. Sendo assim, é apropriado refletir sobre a utilização de estratégias de manejo para longo prazo, como um efetivo ordenamento e planejamento ambiental para as futuras ocupaçóes.

Em relação aos materiais e métodos utilizados no presente estudo, ressalta-se que o equipamento GPS-RTK é uma ferramenta de muita eficiência e precisão e que permite uma obtenção de numerosos dados com uma extrema agilidade, tanto que todos os dados de posicionamento utilizados neste trabalho, referentes ao uso do GPS, puderam ser obtidos em apenas um dia em campo. Embora haja possibilidade de erro, este pode ser bastante minimizado. O ideal é que ocorra a obtenção de todos os dados em um único dia, de preferência com céu aberto e sem prédios e construçóes altas ao redor. Neste trabalho, foi tomado este cuidado, além de ter sido feita uma averiguaçáo da precisão dos dados ao comparar um caminho realizado com o GPS-RTK e com um nivelamento, conforme foi apresentado na metodologia. Por fim, esse método de comparação de diversas linhas de referência móveis (dunas adjacentes e água) e fixa (orla urbanizada), bem como da interpolaçáo da linha de dunas, se mostrou bastante eficiente para os questionamentos realizados. Tal método pode ser replicado para outras praias que apresentem características aproximadamente retilíneas e também pode ser utilizado novamente na praia do Hermenegildo como forma de monitoramento e acompanhamento da erosão nesta praia.

\section{AGRADECIMENTOS}

Os autores do presente trabalho agradecem a Matheus de Oliveira, Paulo dos Santos Freitas, Luiz Rota e Daniesse S. Kasanoski pelo auxílio e apoio nos trabalhos e na logística de campo, a Priscila Teixeira pela contribuição com dados anteriores e aos professores Lauro Calliari e João Nicolodi pelas consideraçôes no andamento do trabalho.

\section{REFERÊNCIAS BIBLIOGRÁFICAS}

Albuquerque, M.D.G. (2013) - Análise espaço-temporal das causas da variabilidade da linha de costa e erosão na praia do Hermenegildo, RS. 127p., Tese de Doutorado, Universidade Federal do Rio Grande do Sul, Porto Alegre, RS, Brasil. Disponível em: http://hdl.handle. net/10183/72241

Boak, E.H.; Turner, I.L. (2005) - Shoreline Definition and Detection: A Review. Journal of Coastal Research (ISSN: 0749-0208), 21(4):688-703, West Palm Beach, FL, USA. Disponível em http://www6.hawaii.gov/dlnr/occl/ files/Shoreline/JCR-VOL21-4.pdf

Calliari, L.J.; Tozzi, H.A.M.; Klein, A.H.F. (1998) - Beach morphology and coastline erosion associated with storm surges in southern Brazil - Rio Grande to Chuí, RS. Anais da Academia Brasileira de Ciências (ISSN: 0001-3765), 70(2):232-247. Disponível em: http://www.praia.log. furg.br/Publicacoes/1998/1998b.pdf

Corseuil, C.W.; Robaina, A.D. (2003) - Determinação altimétrica através de sistema de posicionamento global. Ciência Rural, 33(5):673-678. doi: 10.1590/S010384782003000400014

Dean, R.G. (1986) - Coastal armouring: effects, principles and mitigation. In: B.L. Edge (org.), Coastal Engineering 1986 Procedings, 3 vol., 2888p., ASCE, Charleston, SC, USA. ISBN: 978-0-87262-600-3 Disponível em: http:// journals.tdl.org/icce/index.php/icce/article/view/4136

Dillenburg, S.R.; Roy, P.S.; Cowell, P.J.; Tomazelli, L.J. 
(2000) - Influence of antecedent topography on coastal evolution as tested by the Shoreface Translation-Barrier Model (STM). Journal of Coastal Research (ISSN: 07490208), 16(1):71-81. Royal palm Beach, FL, U.S.A.

Dillenburg, S.R.; Tomazelli, L.J.; Barboza, E.G. (2004a) - Barrier evolution and placer formation at Bojuru southern Brazil. Marine Geology, 203(1-2):43-56. doi: 10.1016/S0025-3227(03)00330-X

Dillenburg, S.R.; Esteves, L.S.; Tomazelli, L.J. (2004b) A critical evaluation of coastal erosion in Rio Grande do Sul, Southern Brazil. Anais da Academia Brasileira de Ciências, 76(3):611-623. doi:10.1590/S000137652004000300014

Esteves, L.S.; Vanz, A.; Silva, A.R.P.; Pivel, M.A.G.; Erthal, S.; Barletta, R.C.; Vranjac, M.P.; Oliveira, U.R. (1999a) Caracterizaçáo das obras de proteção costeira no balneário do Hermenegildo, RS, Brasil. VII Congresso da ABEQUA, Porto Seguro, BA, Brasil. Disponível em: http://www. abequa.org.br/trabalhos/viiabequa_heo001.pdf

Esteves, L.S.; Vranjac, M.P.; Barletta, R.C.; Pivel, M.A.G.; Erthal, S.; Vanz, A.; Silva, A.R.P.; Oliveira, U.R. (1999b) - Impacto de um evento de alta energia nas obras de proteção costeira no balneário do Hermenegildo, RS, Brasil. VII Congresso da ABEQUA, Porto Seguro, BA, Brasil. Disponível em: http://www.abequa.org.br/ trabalhos/viiabequa_zco012.pdf

Esteves, L.S.; Pivel, M.A.G.; Silva, A.R.P.; Barletta, R.C.; Vranjac, M.P.; Oliveira, U.R.; Vanz, A. (2000) Beachfront owners perception of beach erosion along an armored shoreline in southern Brazil. Pesquisas em Geociências (ISSN: 1518-2398), 27(2):97-109, Porto Alegre, RS, Brasil.

Esteves, L.S.; Oliveira, U.R.; Silva, A.R.P.; Vranjac, M.P.; Pivel, M.A.G.; Vanz, A.; Barletta, R.C. (2003) Seasonal changes in beach profile inducing the response of beachfront owners in southern Brazil. Journal of Coastal Research (ISSN: 0749-0208), Special Issue 35 (Proceedings of the Brazilian symposium on sandy beaches: morphodynamics, ecology, uses, hazards and management): 557-563, Itajaí, SC, Brasil.

Esteves, L.S.; Teixeira, P.; Williams, J. (2008) - Managing coastal erosion: from long-term coastal evolution to seasonal shoreline changes. IAHS-AISH publication (ISSN: 0144-7815), 325 (International Commission on Continental Erosion, Symposium, Christchurch, NZL, 2008): 516-523.

Esteves, L.S.; Santos, I.R. (2001) - Impacto econômico da erosão na praia do Hermenegildo (RS), Brasil. Pesquisas em geociências (ISSN: 1518-2398), 28(2):393-403. Porto Alegre, RS, Brasil.

Koerner, K.F. (2009) - Variação espaço-temporal em médio e curto termo da orla do balneário do Hermenegildo, RS. 60p., Monografia de Conclusão de Curso. Universidade Federal do Rio Grande, Rio Grande, RS, Brasil. Não Publicado.

Koerner, K.F.; Oliveira, U.R. (2010) - Impacto de estruturas de contenção sobre a orla do balneário do Hermenegildo, RS. Anais do Congresso Brasileiro de Oceanografia CBO'2010, Rio Grande, RS, Brasil.

Koerner, K.F. (2012) - Alternativas de manejo para o problema da erosáo costeira no balneário do Hermenegildo, Rio Grande do Sul. 156p., Dissertação de Mestrado, Universidade Federal do Rio Grande, Rio Grande, RS, Brasil. Disponível em: http://www.labgerco.furg.br/ ppgc/file/dissertacoes/karl.pdf

Kraus, N.C. (1988) - The effects of seawalls on the beach: An extended literature review. Journal of Coastal Research (ISSN: 0749-0208), SI 4:1-28, Charlottesville, VI, U.S.A.

Kraus, N.C.; McDougal, W.G. (1996) - The effects of seawalls on the beach: Part I, an updated literature review. Journal of Coastal Research (ISSN: 0749-0208), 12(3):691-701, Fort Lauderdale, FL, Brasil.

Lima, L.G.; Dillenburg, S.R.; Medeanic, S.; Barboza, E.G.; Rosa, M.L.C.C.; Tomazelli, L.J.; Dehnhardt, B.A.; Caron, F. (2013) - Sea-level rise and sediment budget controlling the evolution of a transgressive barrier in southern Brazil. Journal of South American Earth Sciences, 42: 27-38. doi: 10.1016/j.jsames.2012.07.002

Lima, S.F., Almeida, L.E.S.B.; Toldo Jr., E. (2001) Estimativa da capacidade do transporte longitudinal de sedimentos a partir de dados de ondas para a costa do Rio Grande do Sul. Pesquisas em Geociências (ISSN: 15182398), 28(2):99-107. Porto Alegre, RS, Brasil.

Linham, M.M.; Nicholls, R.J. (2010) - Technologies for climate change adaptation - Coastal erosion and Flooding. 150p., UNEP Risø Centre on Energy, Climate and Sustainable Development. Roskilde, Dinamarca. ISBN: 978-87-550-3855-4. Disponível em: http:// tech-action.org/Guidebooks/TNA_Guidebook_ AdaptationCoastalErosionFlooding.pdf

Machado, A.A.; Calliari, L.J.; Melo, E.; Klein, A.H.F. (2010) - Historical assesment of extreme coastal sea state conditions in southern Brazil and their relation to erosion episodes. Pan-American Journal of Aquatic Sciences (ISSN: 1809-9009), 5(2):277-286. Disponível em: http://www. panamjas.org/pdf_artigos/PANAMJAS_5(2)_277-286. pdf

Machado, A.A.; Calliari, L.J. (2011) - Mudanças na zona costeira do Rio Grande do Sul: situaçáo atual e perspectivas. Relatório final do II Workshop Brasileiro de Mudanças Climáticas em Zonas Costeiras, 107p., Salvador, BA, Brasil. Disponível em: http://www.mudancasclimaticas. zonascosteiras.furg.br/workshop/images/II_Workshop_ Relatorio_Final.pdf

NRC - National Research Council (1990) - Managing Coastal Erosion. 198p., The National Academies Press, Washington, DC, EUA. ISBN: 0-309-04143-0. Disponível em: http://www.nap.edu/openbook. php? record_id $=1446$

Parise, C.K.; Calliari, L.J.; Krusche, N. (2009) - Extreme storm surges in the south of Brazil: atmospheric conditions and shore erosion. Brazilian Journal of Oceanography, 57(3):175-188. doi: 10.1590/S167987592009000300002

Pereira, P.S.; Calliari, L.J.; Barletta, R.C. (2010) Heterogeneity and homogeneity of Southern Brazilian beaches: A morphodynamic and statistical approach. Continental Shelf Research, 30(3-4):270-280. doi: 10.1016/j.csr.2009.11.007 
Pilarczyk, K.W. (1990) - Coastal protection: proceedings of the Short Course on Coastal Protection, Delft University of Technology, 500p., A.A. Balkema, Rotterdam, Holanda. ISBN: 90-6191-127-3.

Plant, N.G.; Griggs, G.B. (1992) - Interactions between nearshore processes and beach morphology near a seawall. Journal of Coastal Research (ISSN: 0749-0208), 8(1):183200, Fort Lauderdale, FL, U.S.A.

Romeu, M.A.R.; Fontoura, J.A.S.; Melo Filho, E.; Machado, V.B. (2011) - Estimativa dos cenários característicos de agitação marítima para a região oceânica do RS utilizando dados de reanálise do modelo WW3. Vetor (ISSN: $0102-$ 7352), 21(1):91-109. Disponível em: http://www.seer. furg.br/vetor/article/view/2568

Speranski, N.; Calliari, L.J. (2006) - Padróes de refração de ondas para a costa do Rio Grande do Sul e sua relação com a erosão costeira. In: D. Muehe (org.), Erosão e progradação do litoral brasileiro, pp.446-454, Ministério do Meio Ambiente: PGGM-Programa de Geologia e Geofísica Marinha, Brasília, DF, Brasil. ISBN: 857738-028-9. Disponível em: http://www.mma.gov.br/ estruturas/sqa_sigercom/_arquivos/rs_erosao.pdf

Teixeira, P.S. (2007) - Subsidios para o Gerenciamento Costeiro por erosáo na falésia do Balneário do Hermenegildo, RS, Brasil. 107p., Dissertação de Mestrado, Universidade Federal do Rio Grande, Rio Grande, RS, Brasil. Disponível em: http://www.oceanfisquigeo.furg.br/ index.php/dissertacoes/46-2007/188-priscila-da-silvateixeira.html

Toldo Jr., E.; Almeida, L.E.S.B.; Nicolodi, J.L.; Martins, L.R. (2005) - Retração e progradação da zona costeira do estado do Rio Grande do Sul. Gravel (ISSN: 16785975) 3(1):31-38. Disponível em: http://repositorio. furg.br:8080/xmlui/bitstream/handle/1/2120/Retração e Progradação da Zona Costeira do Estado do Rio Grande do Sul.pdf?sequence $=1$

Tomazelli, L.J.; Villwock, J.A.; Dillenburg, S.R.; Bachi, F.A.; Dehnhardt, B.A. (1998) - Significance of presentday coastal erosion and marine transgression, Rio Grande do Sul, Southern Brazil. Anais da Academia Brasileira de Ciências (ISSN: 0001-3765), 70(2):221-229, Rio de Janeiro, RJ, Brasil.

Tomazelli, L.J.; Villwock, J.A. (2000) - O Cenozóico no Rio Grande do Sul: Geologia da Planície Costeira. In: M. Holtz, \& L.F.D. Ros, (org.) - Geologia do Rio Grande do Sul, 375-406, CIGO - Centro de Investigação do Gondwana, Instituto de Geociências, Universidade Federal do Rio Grande do Sul, Porto Alegre, RS, Brasil.

Tozzi, H.A.M. (1999) - Influência das Tempestades Extratropicais sobre o estoque subaéreo das praias entre Rio Grande e Chui, RS. 115p., Dissertação de Mestrado, Universidade Federal do Rio Grande do Sul, Porto Alegre, RS, Brasil. Não Publicado.

USACE - United States Army Corps of Engineers. (2008) Shore Protection Projects. In: USACE, CoastalEngineering Manual (EM 1110-2-1100, Parte V, Cap.3), CERC Coastal Engineering Research Center, Washington, DC, USA. Disponível em: http://140.194.76.129/ publications/eng-manuals/EM_1110-2-1100_vol/ PartV/PartV.htm

Vidal, F.D.C. (2008) - Vamos ao Hermenegildo? 116p., Editora e Gráfica Universitária PREC - UFPel, Pelotas, RS, Brasil. ISBN: 9788571923898. 